\title{
Schauen Sie bei Wilhelm Conrad Röntgen vorbei!
}

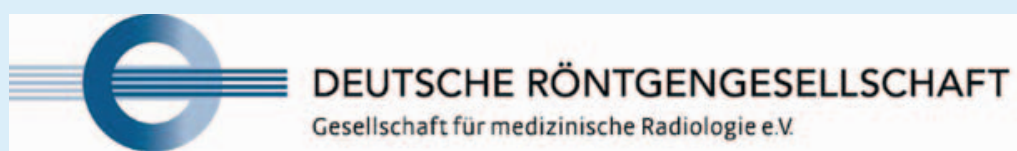

Aufgrund der COVID-19-Pandemie gestalten sich viele Bereiche des öffentlichen Lebens anders als gedacht. So auch das diesjährige Röntgen-Jubiläumsjahr. Auf die große Eröffnungsfeier an Röntgens 175. Geburtstag am 27. März musste das Röntgen-Geburtshaus leider verzichten. Diese wird im November dann nachgeholt - dem Monat, in dem sich die Entdeckung der X-Strahlen zum 125. Mal jährt. Und in der Zwischenzeit? Können Sie in Röntgens Geburtshaus in Remscheid-Lennep vorbeischauen und mehr über den ersten Nobelpreisträger für Physik erfahren. Seit dem 25. Juni steht die dortige Publikumsausstellung für neugierige Besucherinnen und Besucher wieder offen.

Interessierte können dort ohne Voranmeldung jeden Donnerstag von 12 bis $18 \mathrm{Uhr}$ kostenlos mehr über den herausragenden Wissenschaftler, Wilhelm Conrad Röntgen, erfahren. Für die Ausstellungsöffnung wurde in Absprache mit dem Gesundheitsamt ein umfangreiches Hygienekonzept entwickelt. „Zu diesem Konzept gehört unter anderem, dass sich maximal sechs Personen gleichzeitig in der Ausstellung aufhalten dürfen - dabei ist ein Mund-Nasen-Schutz obligatorisch. Des Weiteren reinigen wir die Displays an den interaktiven Stationen regelmäßig mit einem speziellen Desinfektionsmittel. Auf Wunsch händigen wir den Besucherinnen und Besuchern gerne Einmalhandschuhe aus. Wir sind Röntgen-Museum. also bestens ausgestattet und freuen uns, wieder Besucherinnen und Besucher begrüBen zu dürfen.", erzählt Dr. Uwe Busch, Direktor des Deutschen Röntgen-Museums.

\section{Wandeln auf Röntgens Spuren}

Im Erdgeschoss des Geburtshauses befindet sich seit 2019 die interaktive Publikumsaus-

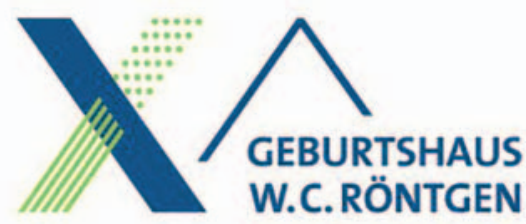

stellung „Auf Röntgens Spuren“. Diese widmet sich ganz der Person Röntgens und seiner Lebensleistung. Hier erfahren Interessierte spannende Details zu Röntgens Biografie und seiner Lebensleistung: Verschiedene Stationen geben Einblick zu Ge-

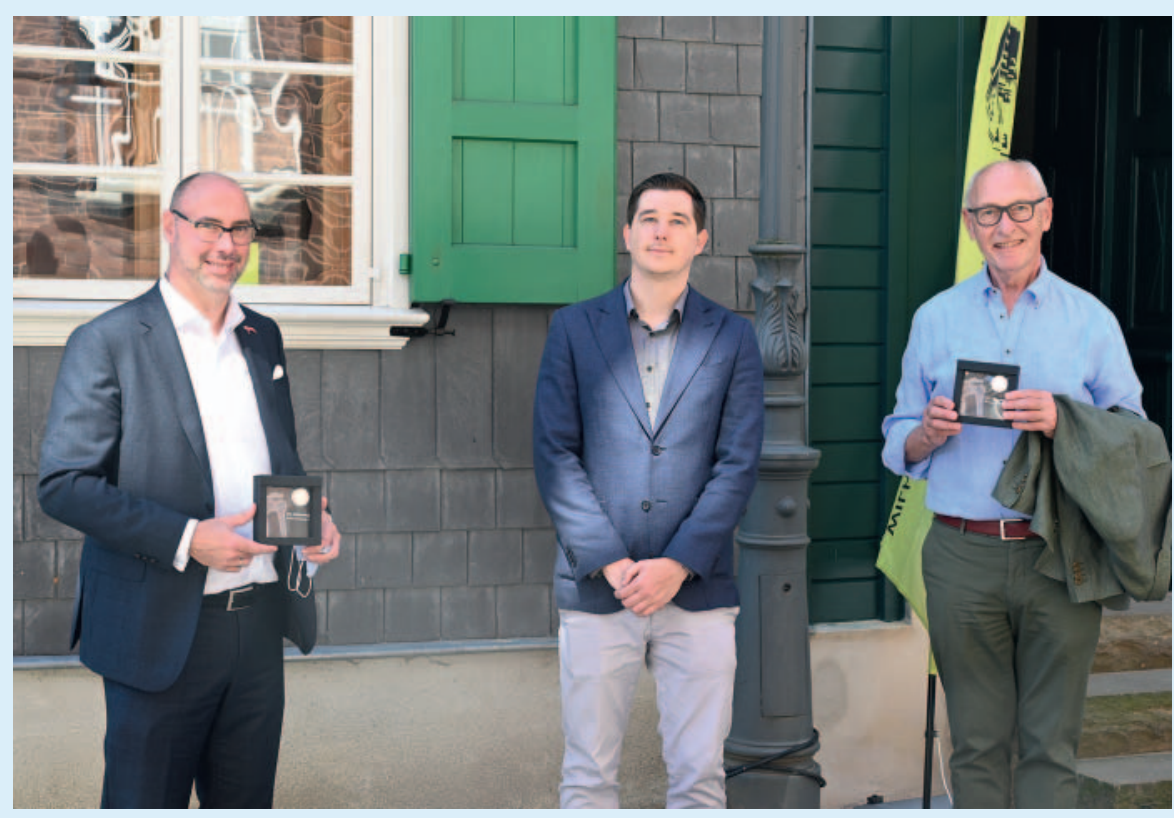

Im Röntgen-Geburtshaus wurden die ersten Sondermünzen zum Röntgenjahr 2020 überreicht (v.I.n.r.): Sparkassen-Vorstandsvorsitzender Michael Wellershaus, Lars Knevels von EuroMint und Prof. Dr. Ulrich Mödder von der Wilhelm-Conrad-Röntgen-Geburtshaus-Stiftung. @ Deutsches 
burt und Familie, Schulzeit und Studium bis hin zu den beruflichen Stationen in Gießen, Würzburg und München. Angelehnt an die ursprüngliche Raumaufteilung um 1840 bieten rund um das zentrale Treppenhaus vier Ausstellungsräume Gelegenheit für eine kleine Entdeckungstour. Besucherinnen und Besucher können dabei die Geschichte dieses besonderen Hauses mit dem Wandel seiner Funktion und Nutzung im Laufe der Zeit nachvollziehen, die weltweiten Netzwerke Röntgens ergründen und sich in einer Schatzkammer auf Spurensuche mit Objekten aus seinem Nachlass begeben. Das Deutsche Röntgen-Museum stellte hierfür aus seinen Archiven eine Auswahl besonderer Dokumente, Urkunden und Briefe zur Verfügung. Neugierig geworden? Dann wandeln Sie auf Röntgens Spuren im Röntgen-Jubiläumsjahr!

\section{Sondermünzprägung zu Ehren Röntgens: Geburtshaus erhält erstes Exemplar}

Anlässlich des doppelten Röntgen-Jubiläums ist eine limitierte Sondermünze der EuroMint GmbH, deren Gestaltung in Kooperation mit der Deutschen Röntgengesellschaft e. V. entwickelt wurde, erschienen. Die auf 500 Stück limitierte 999er

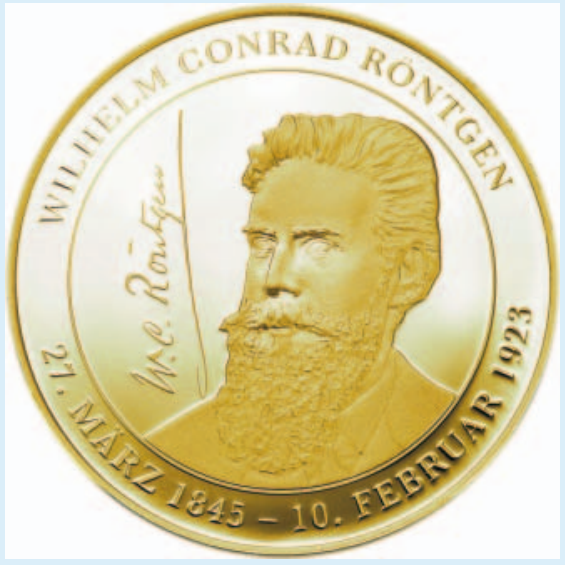

Die Vorderseite der auf 50 Stück limitierten 999,9er Feingoldprägung zeigt Wilhelm Conrad Röntgen. (c) EuroMint GmbH.

Feinsilberprägung $(69,00 €)$ besitzt einen Durchmesser von 30 Millimetern und ein Gewicht von 8,5 Gramm. Von der 999,9er Feingoldprägung $(899,00 €)$ sind exklusiv 50 Exemplare erhältlich, welche in Handarbeit gefertigt wurden.

Im Rahmen der Wiedereröffnung der Publikumsausstellung erhielt das Geburtshaus am 25. Juni das erste Exemplar dieser Sonderprägung. An diesem Tag startete auch der Verkauf in der Lenneper Filiale der Sparkasse Remscheid.

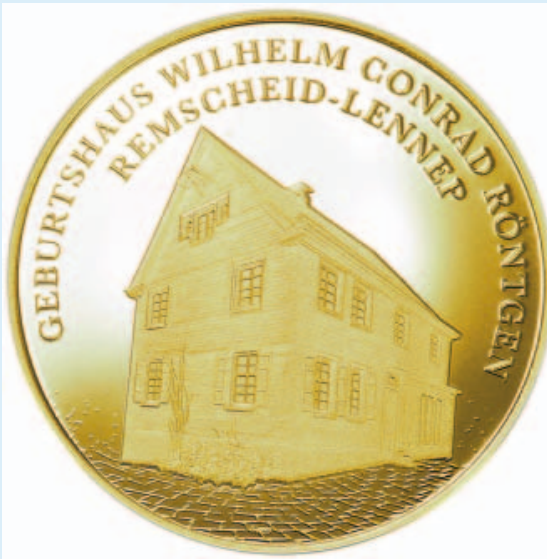

Auf der Rückseite der auf 50 Stück limitierten 999,9er Feingoldprägung ist das Röntgen-Geburtshaus zu sehen. (c) EuroMint $\mathrm{GmbH}$.

\begin{tabular}{|l|l|}
\hline Wo? & $\begin{array}{l}\text { Gänsemarkt 1, } \\
42897 \text { Remscheid }\end{array}$ \\
\hline Wann? & $\begin{array}{l}\text { Jeden Donnerstag von 12 bis } \\
18 \text { Uhr ohne Voranmeldung } \\
\text { An allen anderen Tagen nur } \\
\text { nach Vereinbarung }\end{array}$ \\
\hline Eintritt: & Frei \\
\hline Ansprech- & Claudia Donth, donth@drg.de \\
partnerin: & \\
\hline
\end{tabular}

